\title{
Estudo da Adesão à Quimioprofilaxia Anti-retroviral para a Infecção por HIV em Mulheres Sexualmente Vitimadas
}

\author{
Study of Adherence to Antiretroviral Chemoprophylaxis for HIV Infection in Sexually Abused \\ Women
}

Jefferson Drezett, Iara Baldacini, Isabelle V. V. Nisida, Valéria C. Nassif, Patrícia C. Nápoli

\section{RESUM0}

\begin{abstract}
Objetivos: embora não existam dados apropriados para estabelecer sua eficácia, alguns serviços tem utilizado, profilaticamente, a terapia anti-retroviral para o HIV nos casos de violência sexual. $O$ objetivo deste estudo foi avaliar a aceitabilidade, tolerância e adesão a um esquema quimioprofilático para o HIV.

Pacientes e método: foram avaliadas 62 mulheres vítimas de estupro e/ou atentado violento ao pudor com coito ectópico anal. Os agressores foram referidos como desconhecidos. A profilaxia foi iniciada dentro das primeiras $48 \mathrm{~h}$ da violência e mantida por 4 semanas, sendo administrados diariamente: zidovudina, $600 \mathrm{mg}$; indinavir, $2.400 \mathrm{mg}$ e lamivudina, $300 \mathrm{mg}$.

Resultados: a taxa de descontinuidade foi de 24,2\%, sendo em 12 casos (80\%) decorrente de intolerância gástrica. Os efeitos colaterais estiveram presentes em 43 casos (69,4\%), sendo as náuseas e vômitos os mais freqüentes. A complexidade posológica e o tempo de uso foram fatores possivelmente associados ao uso inadequado das drogas, ocorrendo em 10,6\% dos casos.

Conclusão: a taxa de descontinuidade da quimioprofilaxia foi semelhante à observada em outras indicações.
\end{abstract}

PALAVRAS-CHAVE: Violência sexual. AIDS. Doença sexualmente transmisivel.

\section{Introdução}

São muitas as definições que têm sido utilizadas para conceituar as diferentes modalidades de crimes sexuais. Todas apresentam dificuldade em atender adequadamente os aspectos médico-legais, jurídicos, psicológicos e éticos que estes crimes envolvem. No entanto, há concordância em admitir que se trata de um contato sexual não-consentido. De forma ampla, o termo "violência sexual" parece atender melhor às situações relacionadas ao período de vida adulta, reservando-se o termo "abuso sexual" para

Serviço de Clínica Médica e Infectologia e Serviço de Atenção Integral à Mulher Sexualmente Vitimada do Centro de Referência da Saúde da Mulher - São Paulo.

Correspondência

Jefferson Drezett

Av. Brigadeiro Luis Antônio, 849, 4o andar.

01317-001 - São Paulo - SP

Fone/Fax (11) 881-5938

e-mail: jdrezett@sti.com.br ocorrências durante a infância e adolescência ${ }^{1,2}$.

Em termos legais, o estupro é definido pelo artigo 213 do código penal como "constranger mulher à conjunção carnal, mediante violência ou grave ameaça". Entende-se por "violência" o emprego de força física para sobrepujar a resistência da vítima e por "grave ameaça" a promessa de efetuar mal capaz de impedir a resistência. A "conjunção carnal” é definida pelo coito vaginal. $\mathrm{O}$ atentado violento ao pudor, artigo 214 , é caracterizado pelo ato libidinoso diverso do coito vaginal, sob as mesmas formas de constrangimento. Aqui se incluem as mordidas, sucção das mamas, manobras digitais eróticas e a cópula ectópica anal ou oral ${ }^{2,3}$.

No Brasil, não existem dados apropriados a respeito dos crimes sexuais. Estima-se que os registros das delegacias e dos Institutos Médico Legais (IML) correspondam a cerca de 10 a $20 \%$ dos casos que realmente acontecem. Nos EUA a situação é semelhante, com taxas de $16 \%{ }^{4}$. Em 
geral, a mulher não registra queixa por constrangimento e receio da falta de compreensão ou interpretação dúbia do parceiro, familiares, colegas, vizinhos e autoridades. Temem o interrogatório policial, o atendimento nos IML, a divulgação pela imprensa e a ameaça de vingança do agressor, caso revelem o ocorrido ${ }^{1}$.

Apesar destas dificuldades, tem havido um crescente esforço, de diferentes segmentos da sociedade, em conhecer a dimensão da violência sexual. Nos EUA, a "Anonymous Sexual Association" estima que ocorra um estupro a cada 6 minutos. $O$ Estudo Nacional das Mulheres calcula que, em 1981, tenha havido cerca de 680 mil estupros violentos entre mulheres ame-ricanas adultas. $\mathrm{O}$ "National Center for the Abused and Neglected Child" refere cerca de 100 mil ocorrências na infância a cada ano ${ }^{1,4,5}$. Quaisquer que sejam os números, todas as estatísticas apontam estes crimes como uma das formas mais freqüentes de violência contra mulheres e crianças. Em função da elevada incidência e das conseqüências biopsicossociais que determinam, os crimes sexuais adquiriram proporções de um complexo problema de saúde pública.

A vítima de violência sexual está exposta a diferentes riscos que podem comprometer sua saúde física e mental. Os traumas físicos e ginecológicos, a gravidez, as conseqüências psicológicas e a possibilidade de desenvolver doenças sexualmente transmissiveis (DST) e a sindrome da imunodeficiência adquirida (AIDS) são os mais importantes ${ }^{6}$. A gravidez geralmente é encarada como uma segunda violência, intolerável para a maioria das mulheres ${ }^{7}$. Apesar de o código penal prever o aborto nestes casos há mais de 50 anos, a interrupção destas gestações tem sido feita de forma excepcional pelos serviços públicos de saúde, agravando sobremaneira a situação destas mulheres ${ }^{1}$.

As conseqüências psicológicas da violência sexual tendem a se tornar mais graves após os 7 anos, idade que a criança passa a compreender os valores morais e sociais relacionados ao sexo. Gualquer disfunção psicossocial na infância pode ser indicativa de abuso sexual. Na mulher adulta, a violência sexual tem sido associada à síndrome da desordem estressante pós-traumática, com sintomas que incluem a angústia, medo, ansiedade, culpa, vergonha e depressão. Podem ocorrer reações somáticas como fadiga, tensão, cefaléia, insônia, pesadelos, anorexia e náuseas. Como repercussões tardias podem-se estabelecer o vaginismo, dispareunia, uso de drogas e álcool, depressão, tentativa de suicídio e outros sintomas conversivos e dissociativos ${ }^{3,5,8,9}$.

Os traumatismos físicos, quando presentes, podem variar desde pequenos hematomas até traumas graves que resultem na morte da vítima. De fato, os exames periciais evidenciam a presença de traumas em cerca de $10 \%$ dos casos de estupro, número similar nos relatos da maioria dos serviços que atendem casos de violência sexual $^{10}$.

Ainda não está devidamente esclarecido o risco de se adquirir uma DST por meio da violência sexual $^{6}$. Estudos recentes têm observado taxas de até $60 \%$ destas infecções, com prevalência de 0,8 a 1,6\% para o HIV ${ }^{11,12,13}$. O Estudo Nacional das Mulheres revelou que a infecção pelo HIV representa a principal preocupação para cerca de $70 \%$ das vítimas de violência sexual ${ }^{4}$. O grau de risco de contrair o HIV depende da condição sorológica do agressor, do tipo de violência sexual e do número de agressores. Limitações metodológicas tornam muito difícil avaliar a soroprevalência entre os que cometem a violência sexual. No entanto, diversos estudos sugerem que estas taxas sejam elevadas. De fato, a soroprevalência para o HIV é aproximadamente 14 vezes maior dentro dos sistemas corretivos americanos, bem como em outros sistemas penitenciários de outros países ${ }^{6,14}$. Estes riscos se elevam significativamente se a mulher apresentar traumas ou úlceras que rompam a integridade da mucosa genital.

Não existem dados claros que possam estabelecer a eficácia da administração profilática de anti-retrovirais nos casos de violência sexual ${ }^{6}$. No entanto, o uso destas drogas tem sido feito com objetivos profiláticos após outras formas de exposição, principalmente nos acidentes ocupacionais. Nestes casos, a literatura tem acumulado evidências suficientes que sugerem a redução das taxas de infectividade pelo HIV. A profilaxia, utilizada em acidentes perfurocortantes entre trabalhadores de saúde, revelou ser eficiente em cerca de $80 \%$ dos $\operatorname{casos}^{15-19}$. A quimioprofilaxia anti-retroviral tem sido recomendada pelo "Center for Diseases Control (CDC)", Ministério da Saúde e Programa de DST/AIDS do Estado de São Paulo para os acidentes ocupacionais entre os trabalhadores de saúde. Além disto, o uso da zidovudina em gestantes soropositivas tem apresentado resultados inquestionáveis, reduzindo drasticamente a transmissão vertical do HIV e demonstrando a eficiência dos inibidores da replicação viral $^{15,18,20-23}$.

Baseados nestas observações, alguns poucos serviços nos EUA e Brasil iniciaram, experimentalmente, o uso de quimioprofilaxia antiretroviral nas vítimas de violência sexual ${ }^{6,7}$. Contudo, não existe até o momento nenhum estudo na literatura que avaliasse a aceitabilidade, 
tolerância e adesão destas mulheres ao tratamento. Assim, o objetivo geral deste estudo foi avaliar a aceitabilidade da quimioprofilaxia anti-retroviral para o HIV em uma população de mulheres sexualmente vitimadas, cujos agressores tem situação sorológica desconhecida.

\section{Pacientes e Método}

No período de janeiro de 1997 a abril de 1998 foram atendidas 146 mulheres vítimas de violência sexual pelo Serviço de Atenção Integral à Mulher Sexualmente Vitimada do Centro de Referência da Saúde da Mulher. Destas 146 mulheres, $62(42,4 \%)$ receberam quimioprofilaxia anti-retroviral para infecção pelo HIV. Foram incluídas no estudo mulheres vítimas de violência sexual que entraram em contato com secreções biológicas e/ou sangue e que procuraram atendimento médico dentro das primeiras 72 horas da violência. Foram incluídos os casos de estupro e/ou atentado violento ao pudor com coito ectópico anal. O período máximo de 72 horas para o início da quimioprofilaxia anti-retroviral foi estabelecido como preconizado pelo "Center for Diseases Control” ${ }^{15,21}$ para situações de exposição ocupacional ao HIV.

As pacientes estudadas foram submetidas à terapia anti-retroviral tríplice, com utilização de zidovudina, indinavir e lamivudina. A zidovudina foi utilizada na dose total de $600 \mathrm{mg} /$ dia, via oral, dividida em 3 doses. O indinavir na dose total de $2400 \mathrm{mg} /$ dia, via oral, dividida em 3 doses. A lamivudina foi dividida em duas tomadas diárias de $150 \mathrm{mg}$ cada, via oral. O tempo total de uso das drogas foi de 4 semanas consecutivas.

Consultas semanais para acompanhamento clínico e laboratorial foram realizadas até o término do uso das drogas. A investigação sorológica para o anti-HIV 1 e 2 foi realizada no momento de entrada no estudo e com 3 e 6 meses após a violência. Foi realizado hemograma de controle semanal no período de utilização das drogas. Os dados clínicos e laboratoriais foram registrados em ficha específica do serviço, précodificada e pré-testada, e posteriormente informatizados. O estudo foi iniciado após avaliação e aprovação da Comissão de Ética e Pesquisa da instituição.

Foram considerados critérios de exclusão ao estudo: a) pacientes com idade inferior a 12 anos, b) antecedente de anemia megaloblástica ou doença vigente, c) hemoglobina inferior a $10 \mathrm{~g} / \mathrm{dl}$ em qualquer momento do estudo, d) sorologia prévia à violência sexual positiva para o HIV,e) sorologia inicial (realizada nas primeiras 72 horas pós-violência) positiva para o $\mathrm{HIV}, f$ ) casos de atentado violento ao pudor sem coito ectópico anal e g) situações de violência sem caracterização apropriada de história de exposição ao HIV.

Com relação a casuística, a idade variou de 12 a 43 anos, com média de 21,3 anos. A distribuição do tipo de violência demonstrou 39 casos de estupro $(64,5 \%), 5$ casos de atentado violento ao pudor $(6,4 \%)$ e 18 casos $(29,1 \%)$ de estupro associado ao atentado violento ao pudor. Não haviam iniciado vida sexual no momento da violência 17 mulheres $(27,4 \%)$. O perpetrador da violência foi um desconhecido em 57 casos $(92,0 \%)$, podendo ser identificado em 5 casos $(8,0 \%)$. O número de agressores variou de 1 a 3 indivíduos, sendo que em 57 casos $(91,9 \%)$ o agressor foi único. Com relação a ocorrência de traumas, em 22 casos $(35,4 \%)$ encontraram-se diferentes situações de rompimento da integridade da pele e mucosa genital, assim distribuídos: 1 hematoma (4,5\%), 1 escoriação $(4,5 \%), 2$ fissuras em fúrcula $(9,1 \%), 1$ laceração superficial do períneo $(4,54 \%), 14$ roturas himenais $(63,6 \%)$, e em 3 casos $(13,6 \%)$ foram encontrados outros tipos de trauma genital.

Foram analisadas as seguintes variáveis: $a$ ) tempo de utilização das drogas, b) taxa de descontinuidade, $c$ ) uso adequado das drogas e d) efeitos colaterais

\section{Resultados}

Do grupo de estudo em que foi introduzida a profilaxia anti-retroviral tríplice, 47 mulheres $(75,8 \%)$ utilizaram as drogas por período completo de 4 semanas (Figura 1). Apesar de 47 casos completarem as 4 semanas prescritas, em 5 casos $(10,6 \%)$ o uso das drogas foi avaliado como inadequado ou não-apropriado. Foram considerados inadequados os casos de suspensão do medicamento por período superior a 24 horas em ao menos um episódio, a ingestão em horários irregulares de um ou mais medicamentos ou o uso de dosagem inferior à prescrita de um ou mais medicamentos.

Do grupo estudado, 19 mulheres $(30,6 \%)$ não relataram a ocorrência de efeitos colaterais às drogas. Contudo, em 43 casos $(69,4 \%)$ observou-se a presença de efeitos adversos, sendo que as náuseas corresponderam a $62,9 \%$ e os vômitos a $56,4 \%$ (Figura 2).

A taxa de descontinuidade da quimioprofilaxia foi de $24,2 \%$, equivalente a 15 casos. $\mathrm{Em}$ 12 casos $(80,0 \%)$ a descontinuidade foi decorrente de intolerância gástrica. Em 2 casos $(13,3 \%)$ a 
interrupção da profilaxia se deu por orientação médica, em virtude de reações colaterais de maior intensidade e gravidade. Um único caso $(6,7 \%)$ interrompeu a profilaxia por não compreender o modo de administração das drogas.

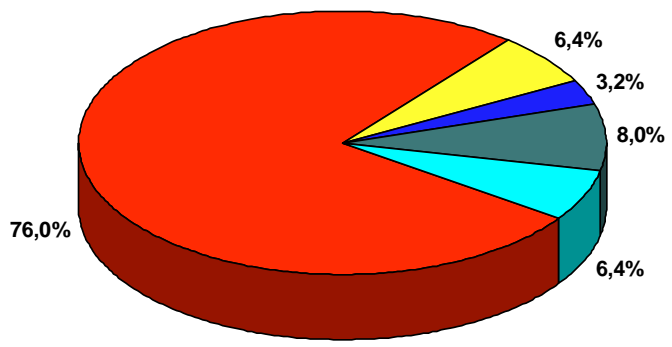

$\square 4$ semanas $(N=47)$

$\square 3$ semanas $(\mathrm{N}=4)$

$\square 2$ semanas $(\mathrm{N}=2)$

$\square 1$ semana $(\mathrm{N}=5)$

$\square<1$ semana $(\mathrm{N}=4)$

Figura 1 - Distribuição do tempo de utilização da quimioprofilaxia anti-retroviral, em semanas completas.

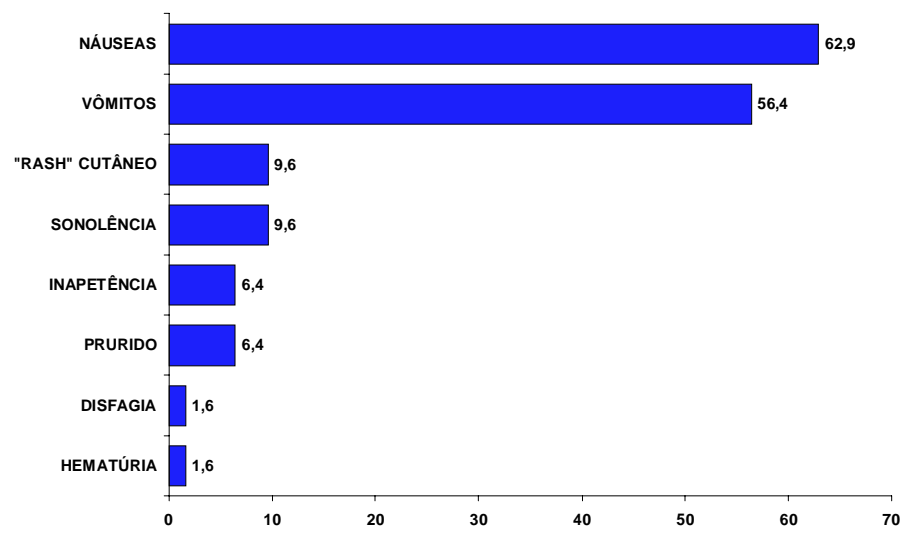

Figura 2 - Prevalência de efeitos colaterais relacionados com a quimioprofilaxia antiretroviral para o HIV (em percentagem, um ou mais efeitos por paciente).

\section{Discussão}

Apesar de a violência sexual atingir a mulher em qualquer idade, cerca de metade dos casos ocorrem durante a adolescência ${ }^{1,5,9,10}$. Neste estudo, a distribuição etária demonstrou uma ocorrência elevada entre mulheres jovens, sendo $38,7 \%$ dos casos entre adolescentes. Este dado deve ser interpretado com reserva, visto que foram excluídas do estudo as ocorrências entre crianças. A violência sofrida em idade precoce muitas vezes acomete a mulher que ainda não iniciou vida sexual. Esta condição determina uma importante elevação no risco de contaminação pelo HIV, visto que a lesão himenal rompe a integridade da mucosa genital ${ }^{6,24}$. Foi considerável o percentual encontrado de mulheres nestas circunstâncias, sendo o defloramento o principal trauma genital observado.

O tipo de violência praticada é outra variável fundamental. A taxa de infectividade do HIV para a mulher em relação heterossexual vaginal única varia de 0,08 a $0,2 \%$. Se o coito for anal, esta taxa se eleva para 0,1 a $0,3 \%$. A presença de sangue ou lesões da mucosa pode aumentar significativamente estes números ${ }^{6}$. Situação ainda mais preocupante se observa na violência sexual, onde os dois tipos de coito são freqüentemente impostos, acompanhados de violência física. Quase $30 \%$ das mulheres estudadas referiram este tipo de prática. Outro fator agravante, a associação com lesões da mucosa genital, esteve presente em mais de $1 / 3$ dos casos.

O fato de o agressor ser desconhecido, na maior parte dos casos, impede que se possa determinar sua condição sorológica para o HIV. Mesmo quando reconhecido ou eventualmente preso, somente um alvará judicial pode determinar e obrigar o agressor a realizar o exame ${ }^{3,6}$. É evidente que o tempo necessário para estas medidas, nos poucos casos possíveis, é impraticável para que se possa iniciar qualquer medida profilática para estas mulheres, dentro dos prazos apropriados. Além disto, há evidências suficientes para se admitir que o agressor tenha grande risco de ser soropositivo, tanto pelos estudos conduzidos entre agressores e presidiários, como pelas taxas até 8 vezes maiores de soroconversão entre vítimas de estupro ${ }^{7,11,12,14}$. Ainda se desconhece o quanto pode significar, em termos de aumento de risco, a violência perpetrada por mais de um agressor. A violência por múltiplos agressores foi observada em quase $10 \%$ dos casos, devendo ser considerada como mais um fator agravante.

Zidovudina e lamivudina são análogos nucleosídeos inibidores da transcriptase reversa viral. Seu mecanismo de ação se baseia na interferência da replicação viral. O indinavir é um inibidor da protease, atuando na clivagem da poliproteína viral. O esquema tríplice associa duas drogas inibidoras da transcriptase reversa e uma droga inibidora da protease, podendo resultar na não-detecção da carga viral ${ }^{15,16,20,21,22}$.

O uso da quimioprofilaxia anti-retroviral para as vítimas de violência sexual tem sido freqüentemente contestado e recebido resistência por parte de alguns autores. Entre os argumentos mais freqüentes, estão a condição de desconhecimento sorológico do agressor e a falta de estudos estatisticamente significativos quanto aos resultados. Entretanto, outras situações de risco equivalente ou potencialmente menor têm recebido atenção considerável na forma de programas específicos, como nos acidentes 
ocupacionais envolvendo profissionais de saúde. É provável que questões culturais e moralistas subjacentes possam interferir no julgamento destes casos. De fato, nos EUA apenas 20\% das vítimas de violência sexual são examinadas pelo médico e $73 \%$ não recebem qualquer informação ou orientação quanto ao risco de DST/AIDS. De forma semelhante, menos de $5 \%$ das mulheres recebem contracepção de emergência nos serviços públicos de saúde 6 .

Neste estudo, considerou-se animador o número de mulheres que completaram o tempo preconizado de uso das drogas, mesmo com a elevada freqüência de efeitos colaterais. A taxa de descontinuidade não se mostrou diferente da observada em outras situações de uso. De fato, nas vítimas de violência sexual esperavam-se taxas de descontinuidade maiores, principalmente pelo uso concomitante da contracepção de emergência e de outras drogas para proteção das DST. Este dado sugere a importância atribuída ao tratamento pelas mulheres e sua grande motivação para completalo. Cumpre ainda ressaltar que nenhum caso manifestou recusa ao uso das drogas na admissão ao estudo. No entanto, a taxa de descontinuidade ainda se mostra significativa, atingindo quase $25 \%$ dos casos. A maioria dos casos foi conseqüência dos efeitos colaterais, principalmente pela intensidade das náuseas e vômitos. Estes dados chamam a atenção para a importância de instituir medidas dietéticas e farmacológicas que possam reduzir e controlar apropriadamente estes sintomas ${ }^{7}$.

A eficácia dos anti-retrovirais para a profilaxia do HIV depende do início precoce de sua introdução, da rigorosidade de sua administração e do tempo adequado de utilização. Em estudos animais, a eficiência destas drogas começa a diminuir após 36 horas da exposição ${ }^{15}$. Entre as mulheres que completaram o tempo orientado de 4 semanas, o uso inadequado dos medicamentos foi de 10,6\%. Este dado pode estar relacionado com o grande número de comprimidos por tomada, complexidade de horários de tomada dos medicamentos e com os efeitos colaterais persistentes. A complexidade posológica resultou em um caso de interrupção da profilaxia por incompreensão da prescrição pela paciente. Este fator pode ser considerado como limitante para mulheres com rebaixamento intelectual que não possam contar com auxílio e apoio domiciliar.

Com relação ao controle sorológico para o anti-HIV 1 e 2, uma grande preocupação é a perda de seguimento destas mulheres, o que torna ainda mais difícil avaliar os resultados da quimioprofilaxia. A maioria dos serviços especializados em atender vítimas de violência sexual refere este problema, com taxas superiores a $60 \%$ de perda de seguimento ${ }^{13}$. Apesar de não se tratar do objetivo deste estudo, o controle sorológico das mulheres que receberam quimioprofilaxia tem sido avaliado. Os resultados preliminares tem demonstrado taxas nulas de soroconversão no grupo que recebeu quimioprofilaxia, ao passo que o grupo controle, com 126 casos, apresenta taxas de 1,6\%. Apesar da limitação estatística da amostragem, estes resultados podem ser vistos como animadores e devem ser considerados como uma alternativa de proteção para o HIV entre estas mulheres. A violência sexual representa uma crise de imensas proporções, devendo os profissionais de saúde mobilizar todos os esforços possiveis para prevenir o degradante sofrimento humano e suas graves conseqüências.

\section{SUMMARY}

Purpose: some medical institutions have been prophylactically ministrating anti-HIV therapy in cases of sexual violence, although there are no appropriate basic facts to establish its efficacy. The aim of the present study was to evaluate the acceptance, tolerance and adhesion of these women under a chemoprophylaxis plan for HIV.

Methods: sixty-two women victims of rape and/or anal intercourse with unknown aggressors have been evaluated. Prophylaxis has been started within the first $48 \mathrm{~h}$ after violence and maintained for 4 weeks, with daily administration of zidovudine, $600 \mathrm{mg}$; indinavir, 2,400 $\mathrm{mg}$ and lamivudine, $300 \mathrm{mg}$.

Results: the discontinuance rate was $24.2 \%$, withe 12 cases (80\%) due to gastric intolerance. The side effects were present in 43 cases (69.4\%), including nausea and vomitting as the most frequent. Complex dosage and time of administration were factors possibly related to the inadequate use of the drugs in $10.6 \%$ of the cases.

Conclusion: the authors concluded that the chemoprophylaxis discontinuance rate was similar to that observed in other indications.

KEY WORDS: Sexual violence. HIV. STD

\section{Referências}

1. Drezett J, Navajas Filho E, Spinelli M, Tonon EMP, Carnevalli CA, Gusmão A, et al. Aspectos biopsicossociais em mulheres adolescentes e adultas sexualmente vitimizadas. resultados da implantação de um modelo integrado de atendimento. Rev Centro Referência 1996; 1: 23-8. 
2. Oliveira J. Código penal. 25 ed. São Paulo: Saraiva; 1987. p. 117-20.

3. Lima SMRR. Estupro. In: Halbe HW, editor. Tratado de Ginecologia. 2 ed. São Paulo: Roca; 1993. p. 970-7.

4. National Victim Center, Crime Victms Research and Treatment Center. Rape in America: a report to the nation. Charleston: Medical University of South Carolina, Department of Psychiatry and Behavioral Sciences; 1992.

5. Mrazek PB. Sexual abuse of children. J Child Psychol Psychiatry 1980; 21: 91-5.

6. Gostin LO, Lazzarini Z, Alexander D, Brandt AM, Mayer KH, Silverman DC. HIV Testing, couseling, and prophylaxis after sexual assault. JAMA 1994; 271:1436-44.

7. Baldacini I, Drezett J, Miranda SD, Nisida IVV, Caballero M, Barros ACD, et al. Prevenção de doenças sexualmente transmissiveis em mulheres vítimas de violência sexual: um modelo de profilaxia. 11th Congreso Latinoamericano de Enfermedades de Transmision Sexual e 5th Conferência Panamericana de SIDA; 1997; Lima, Peru. Libro de resumenes. p. 90.

8. Burgess AW, Hartman CR, McCormack A. Abused to abuser: antecedents of socially deviant behaviours. Am J Psychiatry 1987; 144:1431-6.

9. Hampton HL. Care of the woman who has been raped. N Engl J Med 1995; 332:234-7.

10.Cohen C, Matsuda NE. Crimes sexuais e sexologia forense: estudo analítico. Rev Paul Med 1991; 109: 157-64.

11.Baldacini I, Drezett J, Miranda SD, Nisida IVV, Ribeiro RM, Pinotti JA. Prevalência de doenças sexualmente transmissiveis em mulheres vítimas de violência sexual. II Congreso Latinoamericano de Enfermedades de Transmision Sexual e 5 Conferência Panamericana de SIDA, 1997; Lima, Peru. Libro de resumenes. p. 181.

12.Jenny C, Hooton TM, Bowers A, Copass MK, Krieger JN, Hillier SL, et al. Sexually transmitted diseases in victims of Rape. N Engl J Med 1990; 322:713-6.
13. Osterholm MT, Macdonald KL, Danila RN, Henry K. Sexually transmitted diseases in victims of sexual assault. N Engl J Med 1987; 316:1024.

14.Gore SM, Bird AG, Burns S, Ross AJ, Goldberg D. Anonymous HIV surveillance whith risk-factor elicitation: at Perth (for men) and Cornton Vale (for women) prisons in Scotland. Int J STD AIDS 1997; 8:166-75.

15.Center For Disease Control. Public health service guidelines for the management of health-care worker exposures to HIV and recommendations for postexposure prophylaxis. MMWR, 1998; 47: 1-28.

16. Gerberding JL. Management of occupational exposures to blood-borne viruses. N Engl J Med 1995; 332: 444-51.

17. Gerberding JL, Henderson DK. Management of occupational exposures to bloodborne pathogens: hepatitis b virus, hepatitis $\mathrm{c}$ virus, and human immunodeficiency virus. Clin Infect Dis 1992; 14: 1179-85.

18.Sanford JP, Sande MA, Gilbert DN. Guia para o tratamento da AIDS-HIV. 5 ed. Rio de Janeiro: EPUC; 1997.

19.Veronesi R, Focaccia R. AIDS entre profissionais de saúde: risco e prevenção. RBCTA 1989; 18: 34-6.

20.Center For Disease Control. Provisional public health service recommendations for chemoprophylaxis after occupational exposure to HIV. MMWR, 1996; 45: 468-72.

21.Center For Disease Control. Sexual Assault and STDs. MMWR, 1993; 42:97-99.

22.Brasil. Ministério da Saúde: Programa Nacional de DST/AIDS. Consenso sobre terapia antiretroviral para adultos e adolescentes infectados pelo HIV. Brasília; 1997.

23. São Paulo. Secretaria de Estado da Saúde - Programa de DST/AIDS. Manual de normas para indicação e dispensação de antiretrovirais para portadores do HIV/AIDS no Estado de São Paulo. São Paulo; 1996.

24.Mcgregor JA. Risk of STD in female victim of sexual assault. Med Aspects Hum Sex 1985; 19: 34-9. 